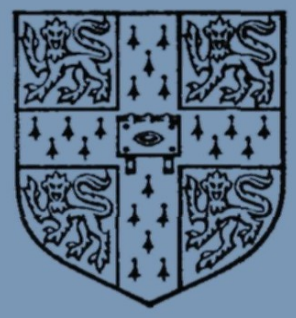

\title{
A First Course in Mathematical Analysis
}

\section{J. C. BURKILI}

A clear, logical and straightforward course, based on the idea of a limit, written for students reading mathematics or physics who already have a working knowledge of the calculus. 'Books of this quality are rare enough to be hailed enthusiastically. ... fresh in conception . . . lucid in style'.

Times Educational Supplement. 22s. 6 d. net

\section{Elementary Real Analysis}

\section{H. G. EGGLESTON}

A rigorous textbook on the theoretical aspects of real variable analysis, covering the work for the first two years of an honours degree course in mathematics. Definitions are stated explicitly and the whole development of the subject is logical and self-contained. There are many examples, with hints for solution, which will be of particular value to students working on their own. $37 s 6 d$. net

\section{Principia Mathematica to $* 56$}

\section{A. N. WHITEHEAD \& BERTRAND RUSSELL}

A paperbound edition of the most famous work ever written on the foundations of mathematics. The abridged text of Volume I contains the material most relevant to an introductory study of logic and the philosophy of mathematics: the whole of the preliminary sections, the whole of Part I, Section A of Part II and Appendices A and C. Cambridge Paperback.

17s. $6 d$. net

CAMBRIDGE UNIVERSITY PRESS 


\section{THE QUARTERLY JOURNAL OF \\ M A T H E M A T I C S}

OXFORD SECOND SERIES

Edited by T. W. CHAUNDY, U. S. HASLAM-JONES, E. C. THOMPSON

\section{CONTENTS}

A. O. Morris: The Spin Characters of the Symmetric Groups

M.S. P. Eastham: On Hilbert Transforms

S. Orey : Non-Differentiability of Absolute Probabilities of Markov Chains.

E. C. Titchmarsh: On the Nature of the Spectrum in Problems of Relativistic Quantum Mechanics (II)

J. Knopfmacher: Universal Envelopes for Non-Associative Algebras

J. B. McLeod : On a Recurrence Formula in Differential Equations

R. Crittenden: Covariant Differentiation

L. Carlitz: Some Identities over a Finite Field

M. S. P. Eastham: An Eigenvalue Problem with the Parameter in the Boundary Condition

Quarterly Journal of Mathematics (Oxford Second Series) is published in March, June, September and December at $18 \mathrm{~s}$. $6 \mathrm{~d}$. net for a single number with an annual subscription (for four numbers) of 65s. post free. Orders may be placed with any bookseller or sent direct to the Publisher.
O X F O R D
U N I V E R S I T Y
P R E S S
AMEN HOUSE, WARWICK SQUARE, LONDON, E. C. 4. 